\title{
A INFLUÊNCIA DA PEDAGOGIA DE SCHOENS- TATT NA PRÁTICA DOCENTE NO SÉCULO XXI
}

\section{THE INFLUENCE OF SCHOENSTATT'S PEDAGO- GY ON TEACHING PRACTICE IN THE 21ST CEN- TURY}

\author{
Gislaine Lopes Monteiro de Souza ${ }^{1}$ \\ Jacy de Araújo Azevedo ${ }^{2}$
}

\begin{abstract}
Resumo: Esta pesquisa teve de atuar na sociedade com suas como objetivo apresentar a pedapotencialidades de forma integra, gogia de Schoenstatt que foi orautêntica e dina exercendo suas ganizada pelo Padre José Kenteresponsabilidades sociais, morais nich na Alemanha no século XX e espirituais. A metodologia usafazendo uma analise de como as da baseia-se em pesquisa biblioconcepções do Padre Kentenich gráfica que apresenta uma síntese pode ajudar os professores em sobre o surgimento da pedagogia sua pratica docente na atualidade Schoenstatt. O artigo está orde. A pedagogia de Schoenstatt ganizado em seções. Na primeira tem por essência a transformação seção trataremos um pouco da do homem despertando nele uma biografia do Padre José Kenteniidentidade livre, decidida e capaz ch e o surgimento da pedagogia
\end{abstract}

1 Graduanda em Pedagogia pelo Centro Universitário Maurício de Nassau (UNINASSAU)

2 Orientadora. Mestra em Educação brasileira pela Universidade Federal de Alagoas (UFAL)

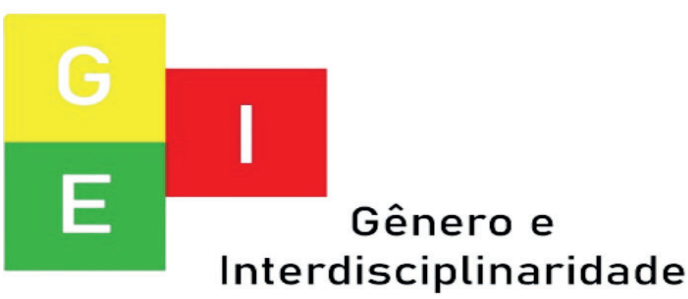


Vol. 02 - n 05 - ano 2021

Editora Acadêmica Periodicojs

de Schoenstatt. Na segunda seção faremos um relato das suas concepções filosóficas e pedagógicas fazendo um paralelo com as tendências pedagogias de Libâneo. $\mathrm{Na}$ terceira seção destacamos alguns lugares onde esta pedagogia é aplicada na atualidade.

Palavras- chaves: Schoenstatt; Pedagogia; Autoeducação; Educação; pratica

Abstract: This research aimed to present the Schoenstatt pedagogy that was organized by Father José Kentenich in Germany in the 20th century, making an analysis of how Father Kentenich's conceptions can help teachers in their teaching practice today. Schoenstatt's pedagogy has as its essence the transformation of man, awakening in him a free identity, determined and capable of acting in society with his po- tential in an integrated, authentic and dynamic way, exercising his social, moral and spiritual responsibilities. The methodology used is based on bibliographical research that presents a synthesis of the emergence of Schoenstatt pedagogy. The article is organized into sections. In the first section we will deal with the biography of Father José Kentenich and the emergence of Schoenstatt pedagogy. In the second section, we will report on their philosophical and pedagogical conceptions, making a parallel with the pedagogical trends of Libâneo. In the third section we highlight some places where this pedagogy is currently applied.

Keywords: Schoenstatt; Pedagogy; Self-education; Education; practice.

\section{INTRODUÇÃO}

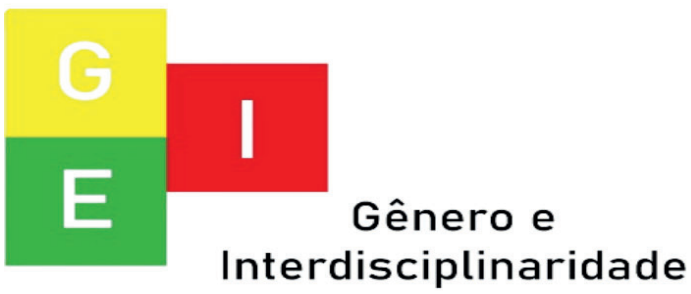


ISSN: $2675-7451$

Vol. 02 - n 05 - ano 2021

Editora Acadêmica Periodicojs

de cada estudante e harmoniza-

Apesar de ter iniciado em 1912, o sistema pedagógico desenvolvido pelo Padre José Kentenich continua sendo aplicado na Alemanha, seu país de origem e em alguns países da Europa e da América Latina. No Brasil este sistema vem sendo praticado na região sul e sudeste, a exemplo do Colégio Mãe de Deus na cidade de Londrina/Paraná que desde sua fundação em 1936 atua com base neste sistema pedagógico, e o Jardim de Maria, escola de Educação Infantil de Santa Maria, no Rio Grande do Sul.

O sistema pedagógico do Padre Kentenich tem como base uma abordagem centrada no relacionamento educador/ educando. Visa contemplar o ser humano em todas suas potencialidades e necessidades considerando que a prática pedagógica lida com os movimentos internos -os com seus projetos pessoais.

STRADA (1989, p. 27), afirma que "o educador é a pessoa chamada a servir a vida do outro, que necessita dessa ajuda para ser ele próprio e desenvolver sua vida em plenitude". A afirmação do autor define para nós profissionais da educação, o quanto somos responsáveis pelo desenvolvimento de nossos educandos. Não devemos esquecer que estamos lidando com vidas e que muitas vezes somos nós, educadores, os únicos colaboradores para o crescimento dos educandos e que por isso temos que antes de tudo nos autoavaliar, perceber nossas limitações, rever conceitos e constantemente buscarmos motivações para que nossa prática docente seja realmente um apoio para o desenvolvimento pleno de nossos alunos.

Hoje mais do que

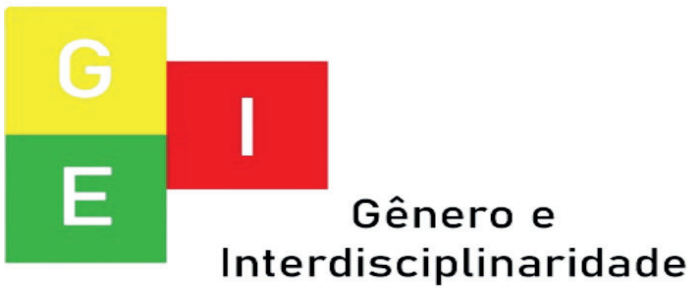


Vol. 02 - n 05 - ano 2021

Editora Acadêmica Periodicojs

nunca, mães e pais, professores em escolas e universidades, pedagogos, psicólogos e sacerdotes, mulheres e homens de boa vontade, se questionam sobre as maneiras de se responder aos formidáveis desafios de quem desempenha tarefas educativas. (STRADA, 1998, p.15)

Comenta-se, com freqüência, a respeito de indisciplina, a falta de interesse dos alunos, a evasão escolar e a violência, consequentemente a desmotivação dos professores frente a esses desafios. De acordo com (LOPES, 2009 p. 2) "ao se fazer uma análise do atual contexto escolar, nota-se que ainda são muito perceptíveis no cotidiano da escola, as reclamações e insatisfações por parte dos professores em relação aos alunos e vice-versa."
Talvez seja difícil dizer

o motivo pelo qual existem tais reclamações e tensões de ambas as partes (professor/aluno). O que não podemos é nos acostumar com essa insatisfação.

Portanto, espertar o interesse para um estudo mais aprofundado da pedagogia de Schoenstatt; e refletir acerca das características dessa pratica docente numa perspectiva de avanço no desenvolvimento da aprendizagem e melhor desempenho do profissional de educação, é isso que pretendemos com nossas pesquisas.

Limitaremos nosso trabalho a uma pesquisa bibliográfica fazendo uma analise de como a Pedagogia de Schoenstatt pode ajudar aos professores em sua prática nos dias atuais.

O artigo está organizado em três seções. na primeira um breve histórico sobre Scho-

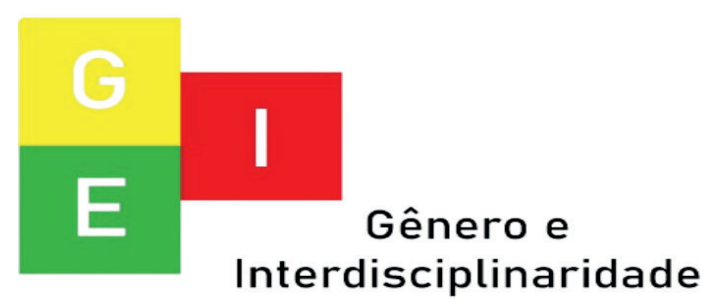


ISSN: 2675-7451

Vol. 02 - n 05 - ano 2021

Editora Acadêmica Periodicojs

enstatt, o Padre José Kentenich e o surgimento de sua proposta pedagógica; na segunda, apresentaremos alguns aspectos filosóficos e uma analise das concepções de Kentenich e outros teóricos, especialmente Libâneo. E na terceira sessão apresentamos algumas contribuições para a prática docente no século XXI.

UM OLHAR SOBRE SCHOENSTATT

"Schoenstatt é um vilarejo situado na parte oriental da pequena cidade de Vallendar/ Alemanha, próximo a Coblença as margens do rio Reno. Literalmente, "Schoenstatt" significa "Lugar Belo", do alemão "eine schoene Statt"' (ANDRACA 2011, p.19). Foi em Schoenstatt que surgiu o sistema pedagógico criado pelo Padre José Kentenich.
Em 18 de novembro de 1885 na cidade de Gymnich na Alemanha, nasceu Pedro José Kentenich filho de agricultores. Aos nove anos, por motivos econômicos, sua mãe o deixou no orfanato na cidade de Oberhausen e o consagrou a Virgem Maria pedindo que ela, daquele momento em diante fosse sua mãe e educadora. Mais tarde o então sacerdote, José Kentenich em sua primeira conferência no Seminário Menor dos Padres Palotinos (atualmente escola superior de teologia em Schoenstatt) afirma,dizendo: “Tudo o que sou e tenho, devo a Mãe de Deus”. (BARBOSA, 2009, p.29)

Desde a infância nutria o desejo de ser sacerdote, sentia uma grande sede de Deus, procurava ao máximo, em tudo se manter puro e agradável a Deus. Seu ingresso ao seminário não foi fácil. Sua mãe não concordava com

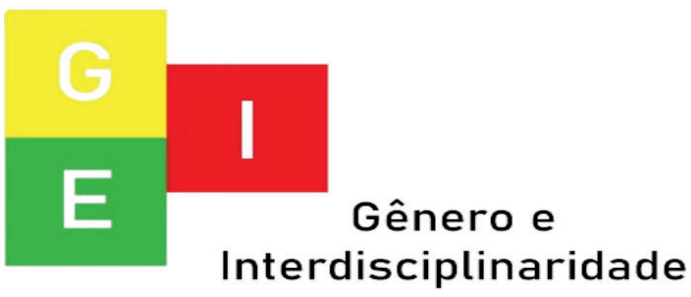


Vol. 02 - n 05 - ano 2021

Editora Acadêmica Periodicojs

a ideia, porém, o diretor do orfanato, o padre Savels a convenceu e José, aos 14 anos entra para o noviciado no seminário dos padres Palotinos em Ehrenbreitstein $^{1}$. Kentenich concluiu o curso secundário em cinco anos, um ano antes dos demais alunos. Tal era sua dedicação aos estudos. Em seguida formou-se no curso de filosofia.

Segundo (BARBOSA, 2009 p.49), o noviciado foi para Kentenich uma experiência que lhe trouxe sérias provações. De acordo com o sistema educacional da época, toda a formação religiosa era dada dentro de um ambiente rígido e frio. O noviço Kentenich tinha um coração ardente, com aspirações profundas. Ele experimentava 1 Vilarejo às margens do rio Reno, onde se localizava o antigo Seminário dos Padres Palotinos em si a angústia espiritual do homem moderno, a angústia do pensar mecanicista.

Em sua busca pela verdade procurou respostas na filosofia para as dúvidas que iam surgindo em sua mente. Era impulsionado a ser um homem livre, ousado, orgânico no pensar, no amar e no viver. Por pensar diferente era visto como um homem orgulhoso. Ninguém compreendia suas ideias, que iam além dos ensinamentos que recebia nas aulas. "Ele vivenciou essa crise por seis anos e foi na pessoa de Maria que encontrou a resposta para a existência do homem e do mundo.” (BARBOSA, 2009 p.51)

Vencida sua crise existencial, Kentenich teria ainda uma provação antes de ser ordenado sacerdote. Desta vez com seus professores e superiores, pois os mesmos quiseram o im-

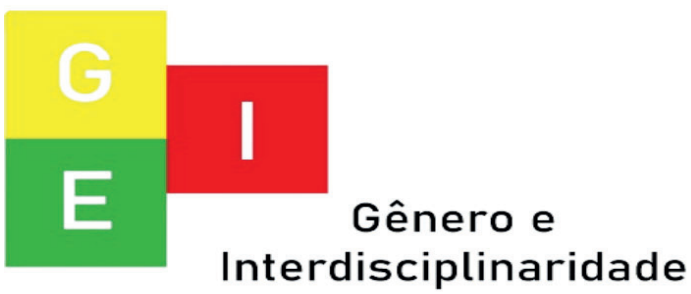


ISSN: 2675-7451

Vol. 02 - n 05 - ano 2021

Editora Acadêmica Periodicojs

pedir de receber a ordenação sacerdotal porque suas indagações e questionamentos em sala de aula os fizeram julgá-lo rebelde e isso chocava o sistema educacional e a formação no seminário naquela época. Porém, depois de longas discussões e por meio de uma eleição seus professores concluíram que José Kentenich seria aprovado para receber o sacramento da ordem e em 1910 foi ordenado Padre.

"Logo no inicio de seu sacerdócio Kentenich lecionava latim e alemão dois anos depois de sua ordenação sacerdotal assumiu o cargo de Diretor Espiritual dos alunos do Seminário." (BARBOSA, 2019, p.27)

Como diretor espiritual sua função era acompanhar os seminaristas com aconselhamentos e confissões, zelar pela ordem, disciplina e distribuição das tarefas no seminário. A no- meação do padre para este novo cargo foi repentina em uma reunião do conselho provincial, ficando assim determinado que J.Kentenich assumisse de imediato o cargo. Anteriormente ele era professor de latim e alemão e seu modo de ensinar era dinâmico e dialógico o que conquistou os alunos os fazendo participar mais ativamente das aulas.

Desse modo indo de encontro ao sistema de ensino da época que era rígido, baseado na aprendizagem estática e de memorização, onde os castigos eram uma forma de manter a ordem e disciplina dos alunos e ainda havia uma série de regras a serem cumpridas obrigatoriamente. Os jovens estudantes que não cumpriam as regras do lugar eram castigados duramente, alguns eram até chicoteados pelos professores. Os alunos se revoltaram contra essas regras e castigos e

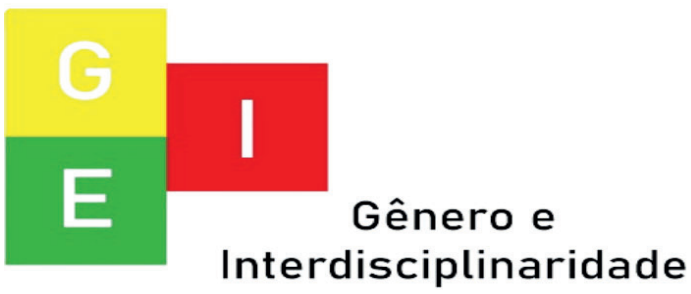


Vol. 02 - n 05 - ano 2021

Editora Acadêmica Periodicojs

o seminário estava vivendo momentos de indisciplina e rebeldia.

Esse contexto nos reporta a educação tradicional onde (LIBÂNEO, 1992, p.4) vai dizer, que "os conteúdos, os procedimentos, a relação professor / aluno não têm ligação com o cotidiano do aluno e muito menos com as realidades sociais. $\mathrm{O}$ que predomina é a palavra do professor e as regras impostas."

A nomeação do padre foi um marco na história daquele seminário, pois o padre Kentenich, como mencionado anteriormente, mantinha um relacionamento muito próximo de seus alunos, porém sem ultrapassar o limite da autoridade e isso sem confundir autoridade com autoritarismo. Colocava-se como exemplo para seus alunos, pois não exigia deles o cumprimento das regras, ao contrário, levava-os à compreensão das mesmas e, por sua colaboração livre, os fazia cumpri-las.

Padre José Kentenich encontrou na sua história, no modo como foi educado e como chegou ao ideal que regia sua vida um caminho para despertar em cada um de seus alunos aos seus anseios de liberdade, os tornando homens íntegros, cidadãos conscientes de seus direitos e deveres frente a uma sociedade massificada.

O padre ousou então, dar a maior liberdade possível, aos seus educandos.

(SCHLICKMANN 2012, p.53) explica: Duas razões moviam o Padre Kentenich a criar espaços e chances para decisões livres: de um lado, isso correspondia ao anseio dos jovens por liberdade e autonomia, respondia à sua receptividade para valores. De ou-




ISSN: 2675-7451

Vol. 02 - n 05 - ano 2021

Editora Acadêmica Periodicojs

tro lado, perseguia assim um dos seus objetivos fundamentais como educador: formar personalidades livres, capazes de se decidirem interiormente com autonomia e de executarem essa decisão. A condição que existia para essa educação no espírito de liberdade era a confiança no potencial positivo de cada um e na atuação divina.

Segundo (Schlickmann 2012 p.46), “o padre deixava-se conduzir por Deus à sua concepção e prática pedagógicas. Seguir o caminho que Deus lhe mostrava através da situação psicológica dos jovens e das exigências daquela época". Em tudo ele buscava ver a ação e a vontade de Deus.

J. Kentenich realizava retiros mensais com os semina- ristas e durante esses retiros pro-

curava conduzir suas palestras de modo que levasse os alunos a uma reflexão acerca de suas responsabilidades e deveres e que só por meio da autoeducação e autoconhecimento seria capaz de suprir suas necessidades de liberdade. Não se trata de convencimento e sim de tornar claro, por meios de exemplo que a autoeducação seria uma abordagem inteligente. Isso os capacitaria para agir e tomar decisões conscientes dos efeitos e das causas dos seus atos.

Em sua primeira palestra aos seminaristas por ocasião de sua nomeação ao cargo de diretor espiritual, Kentenich diz:

Queremos aprender. Não somente vós, eu também. Aprenderemos uns dos outros, pois nossa aprendizagem nunca há de cessar, principalmente em se tratando da arte da autoeduca-

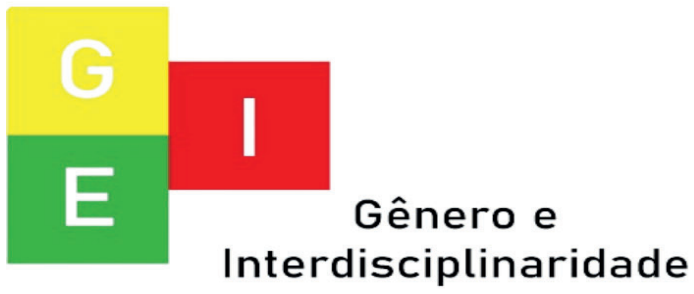


ISSN: 2675-7451

Vol. 02 - n 05 - ano 2021

Editora Acadêmica Periodicojs

ção, que é obra de toda a nossa

vida. (essa palestra logo se trans-

formou no documento de Pré-

-fundação ${ }^{2}$ da obra de Schoens-

tatt). (KENTENICH 1012, p.15)

Com essas palavras o

padre se inclui no processo de aprendizagem e deixa claro para

seus alunos a importância da au-

toeducação para alcançarem o

conhecimento e a própria apren-

dizagem. Podemos pensar que a

autoeducação é importante para

nossa prática e que só por meio

de nosso exemplo é que conse-

guimos motivar nossos alunos a

se autoeducarem.

Os pensamentos e concepções do padre Kentenich, suas palestras e o modo com ele fazia as pessoas que o ouviam refletir

2 Conferência do Pe. José Kentenich, ao se apresentar como diretor espiritual dos seminaristas, em Schoenstatt, em 27 de outubro de 1912. Nela, se apresenta o programa de sua pedagogia, que vai desenvolver na Obra de Schoenstatt. sobre seus ideais e modo de vida era contrário as ideologias Nazistas e em 1941, sob a acusação de inimigo de Hitler, a GESTAPO prende José Kentenich quando pregava em um retiro para os sacerdotes em Schoenstatt. Inicialmente fica preso cerca de um mês numa prisão improvisada em um cofre de banco na cidade de Coblença/Alemanha.

O médico da prisão, a pedido de uma Irmã de Maria $^{3}$ que trabalhava no Posto de Saúde, prontificou-se a examinar o padre Kentenich (condição exigida pela Gestapo) e declará-lo incapaz para o Campo de concentração em vista de sua idade avançada, 56 anos,

3 O Instituto Secular das Irmãs de Maria de Schoenstatt faz parte da Obra Internacional de Schoenstatt, fundada pelo Servo de Deus Pe. José Kentenich, em $1^{\circ}$ de Outubro de 1926, Alemanha. Carisma: ser uma viva presença de Maria na Igreja e no mundo.




ISSN: 2675-7451

Vol. 02 - n 05 - ano 2021

Editora Acadêmica Periodicojs

e de uma deficiên-

cia pulmonar, que

o incapacitava para

serviços forçados.O

prisioneiro, no caso,

o padre Kentenich,

deveria fazer um re-

querimento solici-

tando ser examinado

por impossibilidade

física.Porém, o Padre

não concordou em

fazer o exame, pois

entendia aquela situ-

ação como a vontade

de Deus em sua vida

(BARBOSA, 2009, P.123)

Então abriu mão de sua

liberdade e foi levado para o campo de concentração em Dachau, ao norte de Munique, permanecendo lá até 1945.

(ANDRACA, 2011, p. 122) Em meio ao "inferno" de Dachau $^{4}$ Naquele lu-

4 Dachau foi o primeiro campo de concentração da Alemanha, para lá eram levados os presos políticos do terceiro Reich (O Terceiro Reich ou Alemanha Na- gar o Pe. Kentenich

desenvolve intensa

atividade dirigindo

espiritualmente mui-

tos companheiros de

prisão, dando pales-

tras e retiros. Além

disso, escreve uma

abundante literatura

ascética e espiritual.

Era a fé em Deus e

sua profunda ligação

com a Virgem Maria

que o mantinha ina-

balável, mesmo nos

momentos mais difí-

ceis Kentenich com-

preendia que era tudo

permissão de Deus e buscava sempre perceber o bem em meio às adversidades que passava.

Ao ser libertado e com o

fim da guerra, o padre viajou por alguns pais, entre 1947 a 1951 viaja à África, América do Nor-

cional-Socialista. É o nome que se dá ao período durante o qual vigorou na Alemanha o regime Nacional-Socialista).

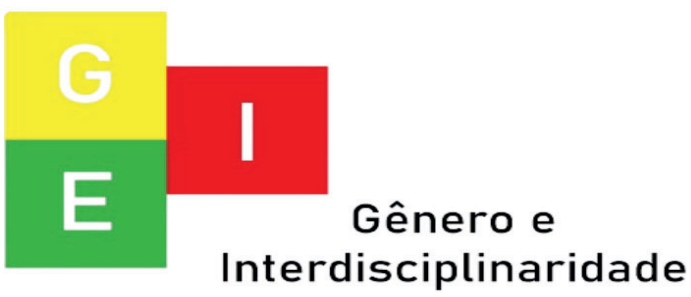


Vol. 02 - n 05 - ano 2021

Editora Acadêmica Periodicojs

te, Brasil, Uruguai, Argentina

e Chile. Em todos esses lugares ele realiza conferências e palestras destacando a importância de educar um novo homem. Neste mesmo período começa a se organizar a Obra de Schoenstatt e o Padre J.Kentenich deseja que a mesma seja reconhecida oficialmente pela igreja, porém, alguns padres e bispos da Alemanha diziam que a Obra de Schoenstatt era contrária a doutrina da Igreja. E isso o levou ao exílio por 14 anos em Milwaukee, Estados Unidos. Mesmo assim a Obra de Schoenstatt continuava a se expandir pelo mundo.

ASPECTOS FILOSÓFICOS E PEDAGÓGICOS DE SCHOENSTATT

A proposta pedagógica de Schoenstatt pode ser caracterizada como, moderna, pois relaciona fé e vida, ciência e teologia e procura dar resposta vital ao fenômeno educativo, ou seja, não procura dar uma resposta baseando-se apenas na teoria (LAWAND 2002).

\section{Aspectos Filosóficos}

Os princípios que orientam a pedagogia Kentenichiana foram inspirados por alguns dos pensamentos de São Tomás de Aquino, padre e filosofo do século XIII considerado um dos principais representantes da Escolástica $^{5}$ e São Francisco de Sales, Doutor da Igreja, e fundador da Ordem da Visitação, titular e patrono da família salesiana, fundada por Dom Bosco, que se inspirou nele ao adotar o nome salesiano. (Andraca, 2011p. 83),

5 p.ext. filteol qualquer filosofia elaborada em função de uma doutrina religiosa.

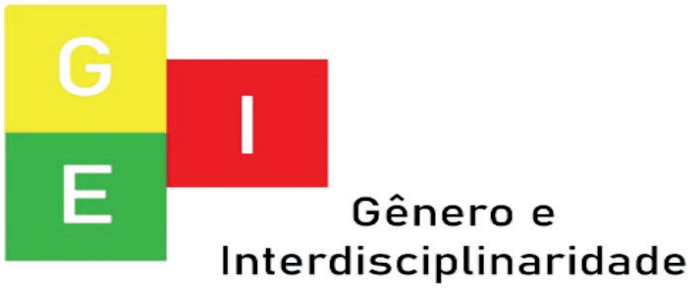


ISSN: 2675-7451

Vol. 02 - n 05 - ano 2021

Editora Acadêmica Periodicojs

explica: "Três princípios inspiram a pedagogia de Schoenstatt. Os dois primeiros são de São Tomás de Aquino e o terceiro de São Francisco de Sales”.

Os princípios de São Tomás de Aquino são: O primeiro "A ordem de ser determina a ordem de agir". A ordem de ser objetiva, tanto natural como sobrenatural, que Deus imprimiu na criatura, deve ser norma e diretriz constante em toda a práxis pedagógica. "A graça não destrói a natureza, mas a pressupõe, cura, eleva e aperfeiçoa". Este princípio refere-se à relação entre a ordem natural e a ordem sobrenatural, entre criatura e criador.

$$
\mathrm{O} \text { terceiro princípio " } \mathrm{O}
$$

amor é a lei fundamental e universal do mundo" o amor deve se tornar a lei fundamental de nossa vida e de nossa ação pedagógica. Pe. Kentenich afirma o amor não só é a maior potência no céu e na terra, mas deve ser considerado

e avaliado como grande poder criador da educação.

( K E N T E N I C H, 1997, p. 7). Segundo ele, o ser humano é uma fonte inesgotável do Amor de Deus e constitui-se em um ser único, portador de muitas e variadas potencialidades. Aos educadores, cabe a sublime missão de conduzi-lo à descoberta dos seus dons e limites como criatura, de sua particularidade como criação predileta e original de Deus e de sua abrangência social como alguém que pode dar e receber, numa troca de valores pessoais e comunitários.

Nesse sentido, a relação educador/educando exige de ambos essa consciência de saber-se amado e chamado à existência por Deus que é o amor e por isso

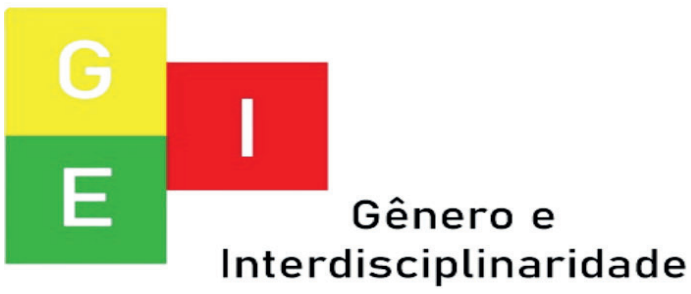


ISSN: 2675-7451

Vol. 02 - n 05 - ano 2021

Editora Acadêmica Periodicojs

este sentimento deve servir como

alicerce para a convivência em sala de aula. E para isso precisa tomar por hábito o autoconhecimento e autoeducação que gera paciência e respeito.

\section{Aspectos Pedagógicos}

No sistema pedagógico de Schoenstatt Deus é o princípio fundamental. E aliado a esse princípio estão três pilares, a saber: o Amor, a Liberdade e a autonomia. A seguir, tomando como base o texto do Projeto Político Pedagógico (PPP) do Colégio Mãe de Deus explicaremos os pilares que sustentam o sistema pedagógico de Schoenstatt.

O Amor: o educador deve amar seus educandos, seu trabalho e isso se expressa na rotina da sala de aula através da dedicação, paciência e principalmente do modo como os alunos são tratados

(Kentenich, 1995 p.

17) esclarece que o espaço educacional onde $\mathrm{o}$ educando sente que é a continuação de seu espaço familiar se torna, para ele, um ambiente saudável, de alegria e de colaboração mútua. Este forte componente afetivo é um dos pilares da atuação docente, na qual o educador é aquele que transfere e conduz o amor de Deus ao educando e vice-versa.

A Liberdade não é a liberdade de fazer o que bem quer e sim, a liberdade de expressar suas ideias, seus sentimentos; é a liberdade de poder escolher conscientemente suas ações visando não só sua própria satisfação, mas, o que é bom para todos. "Continuamente deve-se proporcionar ao educando situações de

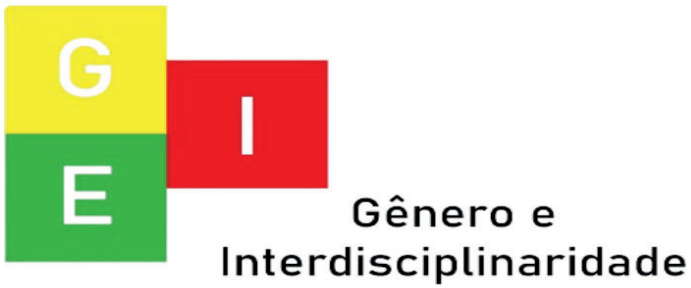


ISSN: 2675-7451

Vol. 02 - n 05 - ano 2021

Editora Acadêmica Periodicojs

escolha e levá-lo à análise dos motivos destas escolhas. Sendo assim, é fundamental, na idade escolar, trabalhar com os educandos a liberdade de expressão, de ação, de complementação". (Kentenich, 1995 p. 17).

O educador precisa estimular seus educando na escolha consciente e em suas tomadas de decisão e isso pode ser praticado na rotina escolar por meio de atividades de grupo, no momento de brincadeiras no pátio e até mesmo em situações de conflitos entre os alunos.

A autonomia, esse é o terceiro pilar da prática pedagógica de Schoenstatt é por meio de intervenções que respeitem a originalidade de cada um que o educador passa segurança ao educando e assim, o mesmo pode realizar suas atividades de maneira autônoma. "O homem novo, é a personalidade autôno- ma, espiritualizada, capaz de e disposta a tomar decisões, responsável e interiormente livre da escravização formalista, bem como de um arbitrarismo total" (KENTENICH，1997，p. 10). A autonomia não pode ser dissociada do amor e da liberdade.

Quando o Padre José Kentenich falou em sua primeira conferência (está conferência resultou no texto do documento de pré-fundação da obra de Schoenstatt): "Queremos aprender. Não somente vós, eu também. Aprendemos uns dos outros, pois nossa aprendizagem nunca há de cessar, principalmente em se tratando da arte da autoeducação, que é obra de toda a nossa vida". (KENTENICH,1912, p. 15). Aqui está claro que Kentenich quer a participação de seus alunos e que a responsabilidade por seus desenvolvimento é tarefa de ambas as partes (professor/ aluno).

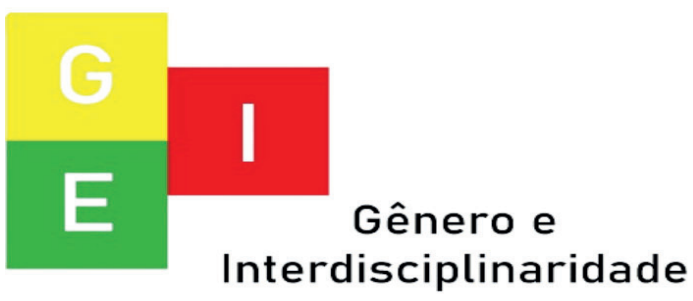


ISSN: $2675-7451$

Vol. 02 - n 05 - ano 2021

Editora Acadêmica Periodicojs

Este é outro aspecto o educador, pois é no exemplo

que ressaltamos da pedagogia do professor que o aluno se insde Schoenstatt que faz referênpira. O aluno busca no professor cia a tendência liberal renovada os valores que o mesmo anunprogressista é o relacionamento cia, ou seja, em outras palavras professor/aluno. Segundo (LIBÂo meu modo de agir precisa esNEO, 1992 p.12) para se garantir tar em conformidade com o meu um clima harmonioso dentro da modo de pensar. E assim se dá a sala de aula é indispensável um relacionamento positivo entre professores é alunos, uma forma de instaurar a "vivência democrática" tal qual deve ser a vida em sociedade. J. Kentenich priorizava essa harmonia em sua sala de aulas.

O padre insiste na ne-

cessidade de autoconhecimento e autoeducação desde o inicio em sua pedagogia. Isso se refere tanto ao professor quanto ao aluno. É por meio desses dois exercícios que se dará o desenvolvimento da aprendizagem e a maior responsabilidade sobre isso recai sobre construção do processo educativo mediante as ações que embora individualizadas, colaboram mutuamente para a construção do todo.

\section{GOGIA KENTENICHIANA PARA A PRATICA DOCEN- TE \\ CONTRIBUIÇÕES DA PEDA-}

São muitos os textos que relatam a prática da teoria Kentenichiana o quanto é atual e serve como apoio para os que a põe em prática.

$\mathrm{O}$ fundador do movimento de Schoenstatt aplicou sua pe-

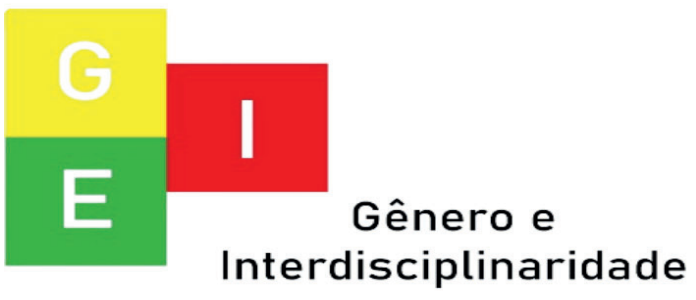


ISSN: 2675-7451

Vol. 02 - n 05 - ano 2021

Editora Acadêmica Periodicojs

dagogia para educar seminaristas, apesar deste fato, seu método de ensino traz um grande direcionamento sobre educar e autoeducar, e tem sido aplicado em diversos níveis de educação, indo da educação básica até a superior. Sendo atualmente utilizada em aproximadamente 40 instituições de ensino espalhadas em diversos países. (BORGES et al, 2016 p. 3, apud GUIMARÃES, 2017)

A pedagogia Kentenichiana foi introduzida com êxito em inúmeras instituições, universidades, cursos técnicos, grupos de vida, comunidades religiosas, escolas, lares, jardins de infância, e cursos de formação para professores em vários países da Europa e da América latina.

No Brasil, o Colégio
Mãe de Deus de Londrina/PR

adotou está prática pedagógica desde sua fundação em 1936. Inicialmente com a formação de professores, passando pela a Escola Normal secundária. Atualmente com uma estrutura pedagógica desde o berçário ao ensino médio com o regime integral curricular. Tomando como referência o documento que constitui o Projeto Político Pedagógico do Colégio Mãe de Deus, a seguir apresentamos uma síntese da prática pedagógica adotada na referida instituição.

Em sua proposta curricular considerando o planejamento relacionado à ação e à avaliação do processo de ensino e aprendizagem alinha de trabalho apresenta os seguintes passos metodológicos: observação da vida, das necessidades das pessoas; comparação dos processos vitais entre si, tendo em conta o

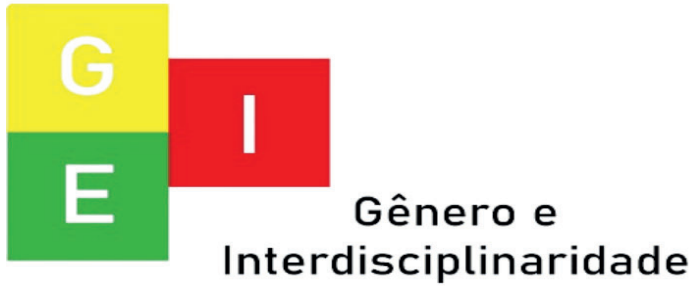


Vol. 02 - n 05 - ano 2021

Editora Acadêmica Periodicojs

presente e o passado dos povos, as várias filosofias e sua repercussão na comunidade; precisar, ou seja, reduzir as observações e as comparações às verdades universalmente válidas, e aplicar colocar em prática as verdades reconhecidas, adaptadas à contemporaneidade, às verdades e ao conhecimento historicamente acumulado e construído pelas ciências e pela cultura pluridimensional.

A meta da Pedagogia de Schoenstatt é a formação da personalidade que compreende e atua com liberdade e autonomia, baseada nos valores cristãos. Para atingir este objetivo, Pe. Kentenich desenvolveu uma pedagogia própria, as chamadas estrelas condutoras, a saber: Pedagogia do Ideal, Pedagogia da Confiança, Pedagogia da
Vinculação, Pedagogia da Aliança e do Movimento ou das Correntes de Vida. (COLÉGIO MÃE DE DEUS, $2015 \mathrm{P}$. 63)

Vejamos na sequência, uma breve explicação de cada uma delas.

- $\quad$ Pedagogia do Ideal: é uma proposta de atitude, da formação do próprio caráter, como personalidade única e, portanto com objetivos pessoais de vida em relação à sociedade. Tem por objetivo: criar ambiente favorável ao processo de autoeducação, despertar, conduzir, orientar e dirigir a autoeducação por meio de um projeto de vida, o ideal pessoal e despertar nos educandos a consciência de valor pessoal e a autoconfiança, proporcionar ao educando meios para que

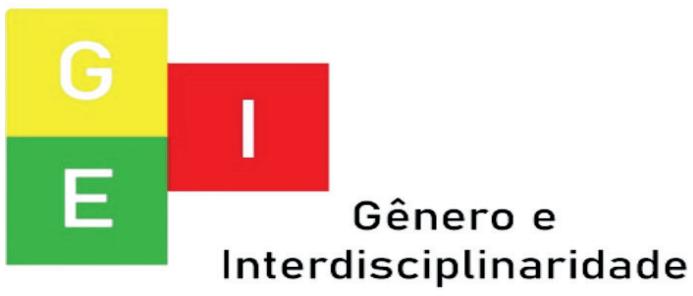


ISSN: 2675-7451

Vol. 02 - n 05 - ano 2021

Editora Acadêmica Periodicojs

ele adquira profunda autoestima; do entender-se como pessoa que

- Pedagogia da vive em sociedade e é chamada

Confiança: valoriza e aplica a a dar sua contribuição de serviço

prática do diálogo. Nesta prática sempre em vista do bem comum;

cabe ao educador: saber ouvir,

- Pedagogia da

conhecer, interpretar e compre-

Aliança: o relacionamento do

ender a linguagem do educando.

educador com o educando se pro-

A pedagogia da confiança pres-

cessa nos moldes de uma Aliança

supõe uma constante autoavalia-

de Amor. O ponto de partida des-

ção do educador que precisa exa-

sa aliança é Maria, mãe de Deus,

minar-se constantemente: vivo o

causa exemplar do ser humano

ensino? O que exijo? A pedago-

profundamente impregnado da

gia da Confiança busca: orientar

graça divina (dimensão espiritual

o educando pelo contato pessoal,

do sistema pedagógico de Scho-

mediante relações e vinculações

enstatt). A pedagogia da Alian-

sadias, valorizar os dotes do edu-

ça tem por objetivo: incentivar

cando, suas peculiaridades;

e conduzir o educando a viver

- $\quad$ Pedagogia do Mosob a proteção de Maria e selar a vimento: consiste em saber utiAliança de Amor com a Mãe de lizar as oportunidades, os acontecimentos, para buscar entre os educandos correntes de vida, iniciativas favoráveis à educação. A pedagogia do movimento objetiva: despertar a responsabilidade social, possibilitando ao educanDeus em seu Santuário de graças, onde ela atua como a grande Educadora e Missionária, conquistar a liberdade, a autonomia e o compromisso social por uma forte consciência de missão para a renovação religiosa, social, po-

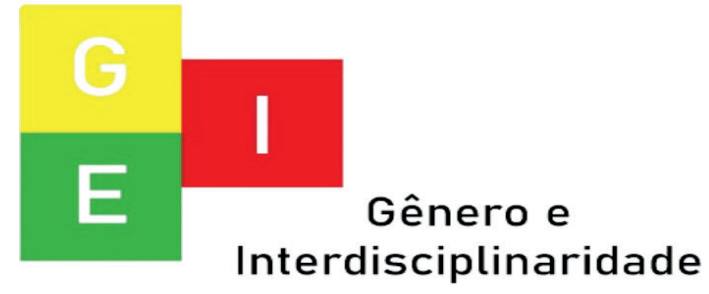


ISSN: $2675-7451$

Vol. 02 - n 05 - ano 2021

Editora Acadêmica Periodicojs

lítica, ética e moral, científica e

cultural do mundo.

Educação à liberdade!

- Pedagogia da Educação do amor! A pedagogia

Vinculação: abrange a vincula- de Schoenstatt expressa claração às pessoas, a ideias, às coisas mente o que acabei de exclamar e à lugares. A vivência desta tríno parágrafo acima. A liberdade plice vinculação confere ao aluno a experiência da escola como e o amor estão entrelaçados no cerne da concepção pedagógica prolongamento do lar. Objetiva do Padre José Kentenich e isso criar e favorecer as experiências foi observado ao longo dos dias naturais, sadias e repletas de vaem que fazia minhas pesquisas lores relacionados com as pessoas, os locais (inclusive o meio ambiente) e às ideias a favor do desenvolvimento dos educandos em todos os âmbitos que vive e convive; ser e dar resposta vital à desvinculação, ao desabrigo geral que o homem experimenta hoje. a negação e o desprezo das vinculações humanas tornam o homem totalmente frio e indiferente, despersonalizado, medroso, inseguro e infeliz.

CONSIDERAÇÕES FINAIS bibliográficas para compor este artigo. Kentenich formulou tais concepções no intuito de atender as necessidades do seminário e dos jovens seminaristas da época, porém, se expandiu pelo mundo e ultrapassou as barreiras do tempo. Uma concepção antiga e nova, pois, mesmo sendo constituída a partir das experiências vividas em meio à educação numa realidade do século $\mathrm{XX}$, onde a relação professor/aluno era rígida, fria, estática e sob a ameaça de duros castigos, o Padre Ken-

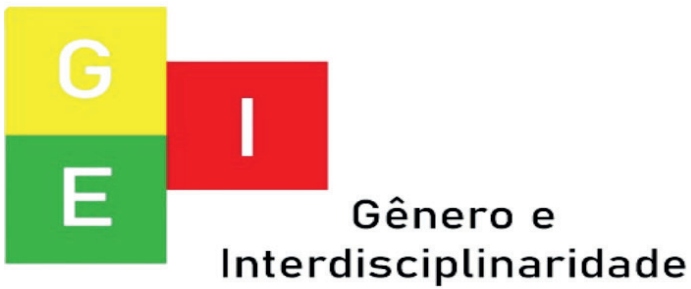


ISSN: 2675-7451

Vol. 02 - n 05 - ano 2021

Editora Acadêmica Periodicojs

tenich, contrariando tudo isso, tinha uma relação mais dialogal, baseada no respeito, no aprender junto. O padre José Kentenich nos deixou um sistema pedagógico que quer despertar em nós a necessidade de nos autoeducarmos, de termos um profundo conhecimento de nosso mundo interior para que assim, por meio de nosso agir, possamos ajudar, direcionar nossos educandos a uma vida plena, organizada, com responsabilidade e conscientes de seus direitos e deveres para consigo e com a sociedade.

Precisamos tomar consciência de nossa responsabilidade enquanto educadores e como somos responsáveis pela formação de nossas crianças e jovens e que por outro lado precisamos também trazer a família para interagir e colaborar no processo de escolarização dividindo as responsabilidades e demandas da educação como um todo.

Algo que se destaca na pedagogia Kentenichiana é a profunda relação com Deus por meio da intimidade com a Virgem Maria na certeza de que ela nos educa e nos ajuda na busca constante pelo autoconhecimento e autoeducação. Isso se constitui a essência, a espiritualidade da pedagogia de Schoesntatt. As linhas condutoras da pedagogia de Kentenich: Pedagogia do ideal, pedagogia do movimento, pedagogia da confiança, pedagogia da aliança e pedagogia da vinculação são a base da atuação para alcançar a autoeducação que vai gerar paciência, afetividade e respeito mútuos.

Precisamos dessas vivências, a busca de um ideal pessoal, o movimento que gera em nós a vida, a confiança, acima de tudo em Deus nosso criador e em nosso potencial humano, pre-

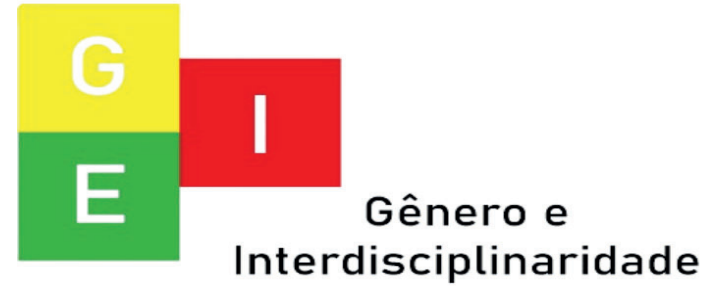


ISSN: 2675-7451

Vol. 02 - n 05 - ano 2021

Editora Acadêmica Periodicojs

cisamos firmar uma aliança que nos conduza, eduque e encoraje a continuar. E unido a tudo isso precisamos dos vínculos: com Deus, consigo mesmo, com as pessoas e com a natureza. Sentindo que tudo gira em torno da vida, que vai gerar amor, respeito e dignidade em toda sua dimensão. Por meio da pratica das assim chamadas estrelas condutoras, que estão interligadas entre se podem se chegar a um relacionamento mais saudável entre as pessoas e no ambiente escolar isso é de grande importância para o bom desenvolvimento das atividades escolares como um todo.

Quando me deparei com o sistema pedagógico do Padre José Kentenich o que me chamou a atenção foi sua história de vida, sua relação com sobrenatural e sua grande preocupação com o homem e sua formação. A proposta pedagógica de Schoenstatt traz um grande ensinamento para quem a pratica, sua dinâmica trabalha a disciplina, a autocorreção e a busca por um objetivo.

Contudo podemos perceber que o estudo mais aprofundado da pedagogia Kentenichiana é relevante para a formação continuada dos educadores, pois essa prática leva o educador a reflexão não apenas no que diz respeito a sua atuação profissional mas, sobretudo a sua própria vida, seus conceitos e atitudes para consigo, com a sociedade e com Deus.

\section{REFERÊNCIAS}

ANDRACA, Pe. Rafael Fernandez de. 150 perguntas sobre Schoenstatt. São Paulo, 2011.

BORGES, Tatiane Angélica Phelipini; GHELARDI, Cristina Fabrício de Melo; LAWAND,

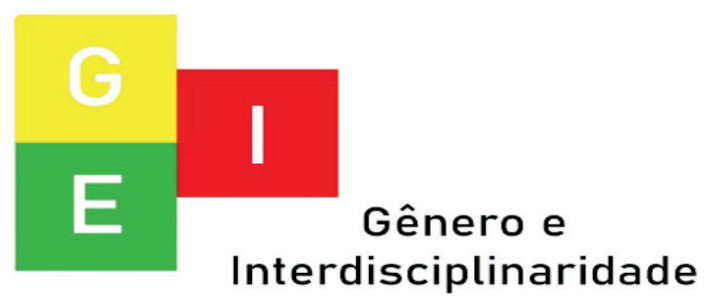


ISSN: 2675-7451

Vol. 02 - n 05 - ano 2021

Editora Acadêmica Periodicojs

Elvira Maria Perides Ir. SISTE- Disponível em: $\quad<$ http:// MA PEDAGÓGICO DE SCHO- www.maededeus.edu.br/a-esENSTATT E SUAS CONTRI- cola/15/pedagogia-de-schoensBUIÇÕES PARA EDUCAÇÃO tatt/23/conheca-a-p edagogia-. PROFISSIONAL NA ÁREA DA html> Acessado em: 23 de Maio SAÚDE. In: $1^{\circ}$ Congresso In- de 2018.

ternacional Schoenstatt de Educação 23 a 27 de Agosto. 2016, Londrina/PR ISSN 2525-5320.

CESPEDES, Cristina Rojas; DIAS, Lívia Ferreira. Um olhar sobre a prática Pedagógica na COLÉGIO MÃE DE DEUS. Procontemporaneidade, Dissertação jeto Político Pedagógico. Institu(Mestrado em Educação), Unito Social, Educativo e Beneficenversidade Federal de Mato Groste Novo Signo, Colégio Mãe de so - Campus de Rondonópolis, Deus - Educação Infantil, EnsiMato Grosso 2014.

no Fundamental e Médio. Londrina - PR, 2015.

KENTENICH, José. Documentos de Schoens-

COLÉGIO MÃE DE DEUS. Petatt. Tradução d o dagogia de Schoenstatt Sistema original "Schoenstatt - Die Pedagógico criado em 1912, por Gründungsurkunden” Santa MaJosé Kentenich Instituto Social, ria/ RS: Ed. Pallotti, s/d. 1995.

Educativo e Beneficente Novo Signo, Colégio Mãe de Deus KENTENICH, José. LiEducação Infantil, Ensino Fun- nhas Fundamentais de uma Pedamental e Médio. dagogia Moderna para o educa-

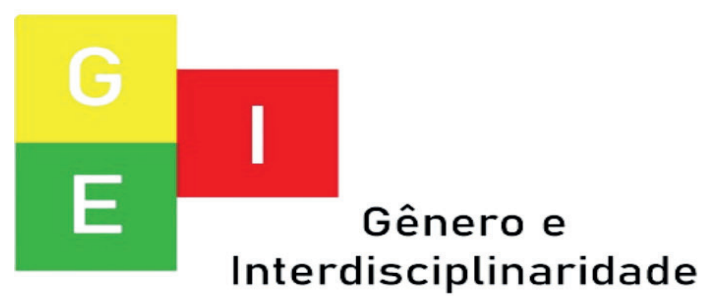


ISSN: 2675-7451

Vol. 02 - n 05 - ano 2021

Editora Acadêmica Periodicojs

dor católico. Santa Maria-RS: gem. Artigo, Ponta Gro s s a Movimento Apostólico de Scho- ～- Paraná, 2009. Disponíenstatt,

vel em: $<$ http://www.diaadiaeducacao.pr.gov.br/portals/pde/

LAWAND, Dioneia. Colégio arquivos/1534-8.pdf.> Acessado Mãe de Deus: aspectos históri- em 6 de junho de 2018.

cos, filosóficos e pedagógicos da educação. Dissertação (Mestrado STRADA, Angel; PONTES, em Educação), Universidade Estadual de Londrina, Londrina, 2002. José. Proposta Pedagógica. $2^{\mathrm{a}}$ edição. São Paulo. Editora C.I, 1998.

LIBÂNEO, José Carlos. TendênSCHLICKMANN, Dorothea M. cias pedagógicas na prática esTempestades de outono 1912: O colar. In: . Democratização inicio de uma revolução interior... da Escola Pública - a pedagoSanta Maria-RS Sociedade Mãe gia crítico-social dos conteúdos. Rainha, 2012.

São Paulo: Loyola, 1992. cap 1.

Disponível em: <http://www. ebah.com.br/content/ABAAAehikAH/libaneo>. Acesso em $15 \mathrm{abr} 2017$.

LOPES, Rita de Cássia Soares.

A Relação Professor Aluno e

o Processo Ensino Aprendiza-

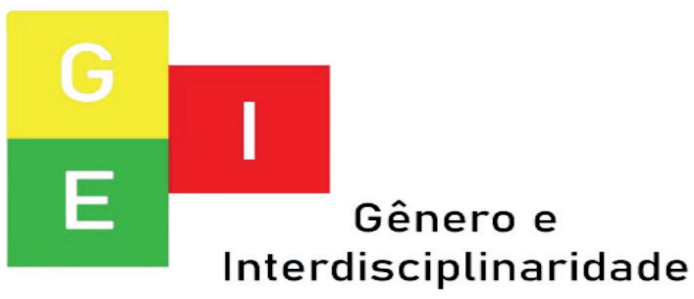

